\title{
LA MÉTRICA Y LOS ESTUDIOS LITERARIOS
}

JosÉ DOMINGUEZ CAPARRós

UNED

Lo que diga sobre el lugar de la métrica en los estudios literarios se va a organizar en dos grandes apartados: primero haré algunas apreciaciones —en las que se incluyen datos históricos y observaciones teóricas- acerca de la función estética de la métrica, y, en general, sobre la métrica como factor literario que, por ser tal, va mucho más allá de la descripción puramente técnica de sus mecanismos. En segundo lugar, propondré algunos puntos que me parecen dignos de ser tenidos en cuenta para el estudio de la métrica - y de la métrica española, especialmente- como disciplina que tiene su lugar en el plan de una semiótica literaria. Resumiendo, se podría decir que, puesto que las estructuras formales de la métrica tienen un evidente poder de creación de sentido, y puesto que la teoría literaria se interesa por comprender cómo la literatura es un sistema organizado de producción de sentido estético, forzosamente la organización métrica será una parcela de esa ciencia literaria general que es la semiótica. La tesis central, así anunciada, puede ser defendida con argumentos históricos y estéticos, que paso a explicar y que constituyen el primero de los puntos enunciados.

Una de las razones para la inserción de la métrica en el proyecto general del estudio teórico de la literatura es que la poética clásica, nuestra ilustre antecesora, asignaba un sentido estético a los mecanismos formales del verso. Como para tantas otras cuestiones, también para esta encontramos el «origen» de nuestro pensamiento en Grecia. 
Bien conocido es el viejísimo problema, planteado por Artistóteles en su $\mathrm{Po}$ ética, de si la poesía exige o no el verso. Sabida es también la solución aristotélica que identifica poesía con imitación y desvincula el verso de la esencia de la literatura -hay naturalistas, nos dice Aristóteles, que escriben en verso y, ciertamente, no pueden llamarse poetas con justicia ${ }^{1}$ - Tiene razón Aristóteles, pero, un poco más adelante, se le cuela la importancia que concede al ritmo en el nacimiento de la poesía, al colocar juntas - y en el mismo nivel de «naturalidad»- imitación, armonía y ritmo, según se desprende de las siguientes palabras:

«Siéndonos, pues, natural el imitar, así como la armonía y el ritmo (pues es evidente que los metros son partes de los ritmos), desde el principio los mejor dotados para estas cosas, avanzando poco a poco, engendraron la poesía partiendo de las improvisaciones." $(1448 b)^{2}$

Hay que pensar, si estamos de acuerdo con Aristóteles, que el estudio del verso, como el de la ficción, es uno de los capítulos fundamentales para la comprensión del arte literario. La cuestión debe ser planteada de la siguiente manera: ¿qué papel desempeña el ritmo? A partir de aquí la descripción métrica adquiere un sentido estético.

No nos puede extrañar, entonces, encontrar en las poéticas de mayor influjo en nuestro pensamiento literario indicaciones para esta unión de lo técnico y lo estético en el verso. Recuérdese a Horacio cuando, en su Arte Poética, se refiere de manera concreta a problemas de métrica en dos ocasiones: la primera, para relacionar asunto poético y forma métrica (por ejemplo: tema heroico y verso hexámetro, teatro y yambo) ${ }^{3}$; la segunda, para anotar los valores estilísticos de la estructura interna de algunas formas concretas: el yambo es un pie rápido, los trímetros yámbicos aceptan el pie espondeo para hacerlos algo más lentos y graves. Que se necesita una preparación a la hora de emitir juicios sobre el aspecto métrico, es lo que nos viene a decir el mismo Horacio en el verso 263 de su Arte Poética:

$$
\text { «Non quiuis uidet inmodulata poemata iudex» }{ }^{4}
$$

I Para la pervivencia del problema planteado por Artistóteles, véase, por ejemplo, EmILIANo Dízz Echarri, Teorías métricas del siglo de oro, Madrid, C.S.I.C., 1970, págs. 99-100; José Dominguez Caparrós, Contribución a la historia de las teorías métricas en los siglos XVIII y XIX, Madrid, C.S.I.C., 1975, págs. 56-59.

${ }^{2}$ Cito por la traducción de Valentín García Yebra, Poética de Aristóteles, edición trilingüe, Madrid, Gredos, 1974.

${ }^{3}$ Véase Arte Poética, vv. 73-93.

4 Anfbal González traduce, en su edición del Arte Poética (Madrid, Taurus, 1987. pág. 138): «El primer crítico que llega no ve en los poemas defectos de armonfa». Para todas estas cues- 
Queda así establecida la tradición que se ocupará de unir la métrica al análisis sistemático de la poesía, se estudie ésta en tratados específicos - las «artes poéticas»- o se incluya en los manuales de gramática, como hace, por ejemplo, el tratadista del siglo IV Diomedes ${ }^{5}$. Por supuesto que existen, ya en la antigüedad, numerosos tratados específicos de métrica ${ }^{6}$.

Que el verso es entendido como algo más que una técnica, y como un fenómeno artístico en que están implicados numerosos hechos retóricos, es lo que se desprende del nombre de ars versificatoria con que frecuentemente se denominan las poéticas medievales. La definición que da Matthieu de Vendôme, por ejemplo, nos proporciona un síntoma de esta amplitud de miras en la comprensión del verso, cuando dice:

«Versus est metrica oratio succincte et clausulatim progrediens venusto verborum matrimonio et flosculis sententiarum picturata, quae nihil diminutum, nihil in se continet otiosum ${ }^{7} . »$

Sin tratar de hacer la historia de la definición y el lugar de la métrica en las distintas propuestas de repartición de tareas en los estudios literarios, no está de más, pienso, echar un vistazo a la manera en que se manifiesta la teoría del verso español en la historia de nuestra filología.

En el siglo de oro predomina la consideración de las cuestiones de métrica en estrecha relación con la poética: Herrera, el Pinciano, Carvallo o Cascales son ejemplos claros, junto a otros. En esto siguen haciendo lo mismo que el

tiones, véase Arte Poética, vv. 250-274. Horacio critica la indulgencia con que se ha juzgado en la poesía latina el aspecto métrico - por ejemplo, en PLAUTo-, y recomienda estudiar continuamente los modelos griegos.

${ }^{5}$ Si se incluye el estudio del aspecto técnico de la poesía en la gramática, es porque ésta se define, siguiendo a VARRÓN, así: «ut Varroni placet, 'ars grammatica, quae a nobis litteratura dicitur, scientia est eorum quae a poetis, historicis oratibusque dicuntur'" (MARIO VICTORINO, en KEIL, VI, pág. 4). El tratado de gramática de Mario Victorino es, en realidad, un tratado de métrica. DioMEDES reserva a la poética el libro III de su Ars grammatica, y en su definición de la poética incluye la métrica: «Poetica est fictae veraeve narrationis congruenti rythmo ac pede conposita metrica structura ad utilitatem voluptatemque accommodata" (KEIL, I, pág. 473). Me parece percibir una pervivencia de esta tradición en la obra de Celso Cunha y Luis F. Linder CinTra, Nova Gramática do Português Contemporâneo, Lisboa, Joao Sá da Costa, 1986, $3^{n}$ ed., cuyo capítulo 22 recoge unas nociones de versificación. También Amado Alonso y Pedro Henriquez Ureña tratan la métrica en su Gramática castellana, Buenos Aires, Losada.

6 Pueden leerse estos tratados en KElL, Grammatici Latini, Leipzig, Teubner, 1857-1870, 7 vols., cuyo tomo VI recoge los Scriptores artis metricae.

7 Véase Edmond Faral, Les arts poétiques du XIle et du XIIIe siecle, Genève, Slatkine, 1982, págs. 110-111. 
Marqués de Santillana o Juan de la Encina en época anterior. Los tratados dedicados exclusivamente a la métrica, como los de Sánchez de Lima o Rengifo, conservan el nombre de arte poética, y Nebrija nos ofrece el mejor ejemplo de inserción de la métrica en un tratado de gramática ${ }^{8}$.

La mejor presentación de las teorías métricas, en el siglo XVIII, se encuentra en La Poética de Luzán, confirmándose la estrecha relación de métrica y poética, característica que cabe observar también en las Lecciones de Retórica y Poética de Jovellanos. El siglo XIX se inaugura con la mezcla de métrica y poética en el trabajo del jesuita Juan Francisco Masdeu, que tiene el mérito de constituir un tratado completo. La unión de métrica y poética es característica muy frecuente en los tratadistas de este siglo: el muy conocido y utilizado Arte de hablar en prosa y verso (1826), de José Gómez Hermosilla, solamente dedica dos capítulos, de los dos volúmenes, a la métrica. Martínez de la Rosa, por ejemplo, hablará de métrica también en su Poética (1827). Vicente Salvá nos ofrece el ejemplo de inserción de la métrica en la gramática (1830).

Andrés Bello es quien puede considerarse el fundador de la métrica española moderna con sus Principios de Ortología y Métrica (1835). Ahí tenemos un tratado íntegramente dedicado a los problemas del verso, y fundado en la prosodia, lo que añade otra nota de modernidad a la obra de Bello. Inaugura así una tradición que se continúa en su discípulo Eduardo de la Barra, y que creo que está en la base de todos los trabajos que en el siglo XX ya conciben los problemas del verso como objeto autónomo de estudio.

En la segunda mitad del XIX tiene lugar una abundante producción de los preceptistas que hacen un resumen de métrica en sus tratados de Retórica y Poética o de Literatura preceptiva. Hay, como es lógico, autores que conceden a la métrica la entidad suficiente como para dedicarles una obra específica. Coll y Vehí (Elementos de arte métrica latina y castellana, 1854), Milá y Fontanais (Arte métrica, 1855), Miguel Agustín Príncipe (Arte métrica, 1862), Eduardo Benot (Prosodia castellana y versificación, 1892) o Menéndez Pelayo, con las referencias a cuestiones métricas en sus obras, son nombres importantes en la constitución de la métrica como disciplina. También en este período crece la preocupación por el estudio de la historia y origen del verso español, preludiando la abundancia de artículos sobre estas cuestiones en el siglo $\mathrm{XX}^{9}$.

${ }^{8}$ Para los detalles en que se basan estas afirmaciones generales, véase E. DIAZ ECHARRI, op. cit., págs. 55-96.

9 Para la historia de la métrica como disciplina en los siglos XVIII y XIX, véase J. Domínguez Caparrós, op. cit., págs. 1-50. 
Alfredo Carballo Picazo destacó, en 1955, que los estudios de métrica adelantan considerablemente en los primeros cincuenta años del siglo $\mathbf{X X}$. Su bibliografía de métrica española así lo prueba, y eso que un poco después aparecerán manuales tan importantes como los de Navarro Tomás (1956) y Rudolf Baehr (1962), o investigaciones rítmicas como las de Rafael de Balbín (1962). Mi bibliografía, que intenta continuar la que en 1956 publicó Alfredo Carballo, demuestra también la abundante producción de estudios métricos en los últimos treinta años ${ }^{10}$. Sobre el carácter de las investigaciones métricas actuales informa igualmente mi trabajo de 1988, Métrica y Poéti$\mathrm{ca}^{11}$.

No se trata, ni mucho menos, de hacer la historia de la métrica española, ni siquiera de dar los nombres más importantes; sólo quería indicar cómo se constituye en disciplina que, estando originariamente muy ligada a la poética, va adquiriendo, a partir del siglo XIX, un perfil más o menos nítido. La consecuencia es que se configura, efectivamente, un dominio bien limitado, pero con el riesgo de que, desde fuera, no se sienta la necesidad de profundizar en las implicaciones estéticas de los fenómenos métricos, y se haga una simple utilización instrumental de recuento.

Sin embargo, el estudio de las formas métricas en la poética, así como las muy numerosas observaciones que sobre el valor estético literario de la métrica pueden encontrarse, tanto en estudios del verso como en escritos de otra índole, tienen que apoyar forzosamente la importancia del lugar de los fenómenos rítmicos en una teoría literaria.

Apuntado ya el argumento histórico (la métrica está estrechamente relacionada con la poética en su historia), entro en el argumento estético: los fenómenos rítmicos y convenciones métricas tienen un papel fundamental en la estética literaria. Esta es una de las ideas centrales que recorren mi trabajo sobre Métrica y Poética, que parte del pensamiento teórico de los formalistas rusos, y se fija principalmente en los trabajos de los últimos treinta años sobre el verso español ${ }^{12}$.

Los formalistas rusos insertan todas sus observaciones métricas en una teoría de la lengua literaria. El citadísimo trabajo de R. Jakobson, Lingüistica y poética, lo formuló, algún tiempo después, en términos tajantes y bien claros:

10 Véase A. Carballo Picazo, «Los estudios de preceptiva y de métrica españolas en los siglos XIX y XX. Notas bibliográficas», en Revista de Literatura, VIII (1955), págs. 23-56; Métrica española, Madrid, C.S.I.C., 1956; J. Dominguez CAPARRós, Contribución a la bibliografía de los últimos treinta años sobre métrica española, Madrid, C.S.I.C., 1988.

11 Véase J. Domf́nguez Caparrós, Métrica y Poética, Madrid, UNED, 1988.

12 Véase op. cit., págs. 40-44 especialmente. 
«En resumen, el análisis del verso se halla por entero dentro del campo de la poética, que podemos definir como aquella parte de la lingüística que trata de la función poética en sus relaciones con las demás funciones del lenguaje ${ }^{13}$."

No sólo históricamente (como antes se vio), sino que teóricamente la métrica se integra en la poética, entendida como teoría de la lengua literaria.

El gran metricista relacionado con el formalismo ruso, V. Žirmunskij, en un trabajo de aquella época, no muy citado - yo tampoco lo tuve en cuenta en 1988-, expone clarísimamente las pautas para la integración de la métrica en un plan de poética moderna. Su razonamiento parte de la idea fundamental de la consideración del objeto artístico en su integridad, no con una forma y un contenido separados. Los artificios métricos tendrán que comprenderse estéticamente. Veamos cómo ocurre esto: el material de la poesía es la palabra, luego la poesía es un uso lingüístico, que se construye siguiendo principios artísticos. La organización estética de los elementos del lenguaje poético supone una estructuración fonética (aquí es donde se sitúa la métrica), sintáctica y léxica. El estudio de los artificios poéticos es tarea de la poética general, o teórica, que se organiza en: fonética poética, que comprende la métrica, los fenómenos de instrumentación (orquestación) verbal, y la entonación poética; morfología poética; sintaxis poética; semántica poética (la palabra como tema poético, los cambios de significado, los artificios de las palabras agrupadas); relación entre un estilo y la historia de la lengua. Pues bien, en este programa general, la métrica puede adquirir una relevancia tal que se apropie de todo el campo de la fonética poética:

«In view of the special importance of metrics for poetry, this chapter of poetic phonetics is sometimes set apart as an independent division correlated with the other principal branches of poetic-sytilistics, composition, and themes; and then the term 'metrics' is often used in the more inclusive sense of poetic phonetics in general $^{14}$, ,

No cabe duda de que la concepción amplia del ritmo incluye todos los hechos fónicos del verso, y es entonces la métrica la encargada de explicar su valor artístico. Valor que se integra en el todo poético de la obra:

13 Véase R. Jakobson, Ensayos de Lingüística General, Barcelona, Ariel, 1984, pág. 361.

14 Véase V. ŽIRMUNSKIJ, The task of Poetics, 1919-1923, en Selected Writings. Linguistic. Poetics, Moscow, Progress Publishers, 1985, págs. 261-319, la cita en págs. 276-277. 
«The harmony between thematic structure and the composition of rhythmical and syntactic units is a particularly characteristic feature of artistic unfolding of the theme: the separate individual themes are connected by semantic parallelism supported, as we have said at the beginning, by the parallelism of language forms in rhythm and syntax ${ }^{15}$.»

La poética, dice más adelante Žirmunskij, tiene que establecer la interconexión de artificios, no solo describirlos en su individualidad. Pues bien, la rima es un fenómeno que ilustra de forma privilegiada tal interrrelación ${ }^{16}$. De la importancia que Žirmunskij concede a la métrica, nos podemos hacer idea si nos fijamos en que, para él, el criterio externo que determina la mayor dependencia o libertad de la intención artística respecto del material verbal es la presencia del verso. Puede pensarse que Žirmunskij, frente a la vieja cuestión de la relación entre verso y poesía, no tendría inconveniente en sostener la obligatoriedad del artificio métrico, según parece desprenderse de una afirmación como la siguiente:

«[...] a lyrical poem in entirely subordinated to the esthetic task in its verbal composition, in the choice and combination of words, both in terms of semantics and sound ${ }^{17} . "$

Téngase en cuenta que, como había dicho inmediatamente antes, el verso es el criterio externo de la función estética del material verbal.

15 Véase op. cit., pág. 275. Las propuestas de análisis literario en que el punto de partida es la métrica no harían más que ilustrar esta idea de ŽirmuNSKIJ. Véanse algunos comentarios a taies propuestas en mi Métrica y Poética, cit., págs. 42-44. Añado ahora la referencia a las observaciones de M. Riffaterre sobre la métrica como uno de los contextos de la poesía: 1.- coloca al poema en una jerarquía tradicional de géneros; 2 - acrecienta, por su regularidad, los contrastes: el contraste es como la renovación de un cliché. Véase Ensayos de estilistica estructural, Barcelona, Seix Barral, 1976, págs. 167-170.

16 Dice exactamente ŽJRMUNSKIJ, quien, como se sabe, escribió un libro clásico sobre la rima en la versificación rusa:

"Thus myme is a phenomenon of verbal instrumentation (as sound repetition); at the same time rhyme is a device of metrical composition defining the boundaries of the line and linking up the lines in higher order metrical units (stanzas); essential for rhyme is the morphological structure of the word (root and suffixal rhymes, grammatically homogeneous and heterogeneous thymes); the vocabulary of rhyming words is a characteristic feature of verbal style.» (Op. cit., páginas 282-283.)

17 Véase op. cit., pág. 282. 
Todas estas afirmaciones, que parecen obvias, no estoy seguro de que guíen la forma en que se comprenden y estudian los artificios métricos.

Si el verso es uno de los índices privilegiados de la poeticidad del lenguaje $^{18}$, no agota, sin embargo, en las propiedades lingüísticas sus características. Sabido es que la dosis de convencionalidad en la elección de sus rasgos no es despreciable, y de esta manera el verso es un hecho histórico, casi institucional, que lo asimila a otras realidades tan importantes de la poética como pueden ser los géneros. El verso, pues, es un hecho de lenguaje, pero de lenguaje convencional (literario).

El aspecto convencional es interesante, entre otras razones, porque garantiza la posibilidad de una métrica comparada. En efecto, como ha observado Jean-Louis Backès, aunque hay datos que llevan a pensar en una dependencia de la métrica respecto del sistema lingüístico, no faltan tampoco grandes márgenes de indeterminación: la lengua no explica todas las elecciones métricas. Es evidente que las técnicas poéticas - y entre ellas la métrica - se pueden importar de una literatura a otra. El dominio métrico tiene, pues, una relativa autonomía. Me parece interesante el párrafo con que J.-L. Backès termina su apartado sobre métrica general:

«On ne saurait assez y insister: l'ensemble de ce que l'on appelle les phénomènes formels ne dépend de manière immédiate et nécessaire ni de la structure des langues, ni des courants d'idées. Toute relation entre phénomènes de ces différents niveaux doit faire l'objet d'une interprétation. Si on la considère comme naturelle, on s'interdit de penser le mouvement historique en littérature ${ }^{19} . \gg$

En mi trabajo de 1988 sobre métrica y poética observé que, en cuanto convención literaria, la forma versificada tiene relaciones con lo social, lo exterior. No se agota el estudio del verso en la descripción linguística y en la objetivación de las normas literarias a que obedece. Muy variados son los campos con los que puede relacionarse la métrica, y esto no debe extrañar cuando la pragmática, la parte de la semiótica que hoy es la protagonista, nos está acostum-

18 No faltan, en modernos estudios de métrica, las observaciones que ponen en relación, de manera explícita, el verso con la función poética del lenguaje. Véase, por ejemplo: M. PAZzaGLiA, Manuale di metrica italiana, Firenze, Sansoni, 1990, págs. 6, 13-14; M. Ramous, La Metrica, Milano, Garzanti, 1988, 2 ed., págs. 15-16.

19 Véase Jean-Louis Backès, Poétique comparée, en Brunel, P. et Chevrel, Y. (eds.), Précis de littérature comparée, París, PUF, 1989, págs. 85-103, especialmente el apartado «Métrique générale», págs. 87-93; la cita en pág. 93. 
brando a mirar con atención al contexto de la obra literaria. Allí me referí a John Lotz y la lista de campos de estudio que relacionaba con la métrica: los estudios literarios, la antropología y etnología (el uso cultural de la forma métrica), la psicología y la estética, la sociología y la historia cultural en general. No voy a repetir afirmaciones de Rowena Fowler, Emilio García Gómez, Jens F. Ihwe, S. Gili Gaya, M. Pagnini..., en que la métrica se pone en relación con lo cultural, lo filosófico o lo psicológico ${ }^{20}$.

Añado solamente el ejemplo de un crítico, T. S. Eliot, que, tenido por padre del formalismo anglosajón, sorprende con una afirmación como la siguiente:

«Pero la decadencia de las estrofas intrincadas nada tiene que ver con la aparición del vers libre. Se había iniciado mucho antes. Solo en una sociedad bien trabada y homogénea, donde hay muchos que trabajan en los mismos problemas, solo en una sociedad como las que produjeron el coro griego, la lírica isabelina y las canciones de trovador, podría llegarse a la perfección en el desarrollo de esas estrofas ${ }^{21}$.»

Se ponen en relación estrofas intrincadas y formas de sociedad. Hay una tentación de interpretar en clave sociológica, como una metáfora, las formas métricas en relación con la forma social. No nos puede extrañar, entonces, que Julia Kristeva haga algo parecido, como habrá ocasión de ver después.

Como conclusión de los argumentos estéticos a favor del interés de la forma métrica, tengo que referirme a la concepción idealista del proceso creador en que parece que el aspecto técnico sólo sirve de estorbo a la expresividad individual. Tal postura, simbolizada por Croce, como es bien sabido, no es apoyada por quienes, al contrario, ven en la técnica precisamente un acicate en el proceso creador. Luigi Pareyson sostiene que la forma métrica incide en la creación según un triple modo:

1. Materia: el poeta encuentra un estímulo para la creación al elegir una forma métrica;

2. Regla: como regla, la forma métrica puede ayudar a llevar al éxito;

20 Véase J. Dominguez Caparrós, Métrica y Poética, cit., págs. 41-42.

21 Véase T. S. ELIot, Criticar al crítico y otros escritos, Madrid, Alianza Editorial, 1967, pág. 252. 
3. Idea: el éxito se convierte en un modelo, las búsquedas técnicas, métrica y formal, «contienen ya el activo e indispensable presagio del ar$t^{22} . »$

La forma métrica es muy distinta en una obra buena y en una obra mala. No se trata de un esquema vacío, sino que la forma externa, en la verdadera obra de arte, se inserta en el corazón mismo de la creación artística:

«Viendo así las cosas, una forma métrica no es la etiqueta común a obras mediocres y obras perfectas, porque, mientras que a las primeras es indiferente, usada más como instrumento que como 'forma expresi$\mathrm{va}^{\prime}, \mathrm{a}$ las obras conseguidas es tan poco indiferente que constituye, por el contrario, un aspecto esencial, inseparable de la totalidad artísti$\mathrm{ca}^{23}$.»

Resumo brevemente lo que llevo dicho: he partido de los lazos históricos que han unido los estudios del verso con la poética, $y$ he pretendido explicar el carácter estético de los fenómenos métricos, tanto si se parte de una poética lingǘstica, como si uno se sitúa en el marco de la convencionalidad histórica. Desde cualquiera de los puntos de partida, la métrica se perfila como dominio bien delimitado - por su vertiente técnica y la consciente elección en un momento preciso-, y rico en implicaciones estéticas.

Pienso que la semiótica literaria nos puede proporcionar el marco teórico mejor pertrechado para integrar los diversos aspectos de la función literaria de la métrica. En efecto, en rápida utilización, con fines sólo ilustrativos, de la propuesta teórica que de esta disciplina hace María del Carmen Bobes Naves ${ }^{24}$, ¿cómo no ver en la sintaxis semiótica el lugar de la métrica descriptiva, la que enumera los esquemas y condiciones de las numerosas

22 Véase L. Pareyson, Conversaciones de estética, Madrid, Visor, 1988, pág. 82.

23 Véase op. cit., pág. 76. Numerosos son los ejemplos que parecen ilustrar esta idea de L. PAREYSON: la gran poesía, efectivamente, lleva asociada una forma métrica considerada como expresión suprema de perfección artística. La épica de Homero se identifica con la manifestación del hexámetro en su forma perfecta; la Divina Comedia, con el endecasílabo y el terceto; Garcilaso de la VEga, con el endecasílabo, y las formas importadas de Italia que, gracias a él, adquieren rango artístico en español; Fray LUIS de LEÓN y la lira; Rubén Darto y la renovación métrica más amplia llevada a cabo en la poesía culta moderna en español; etc... Podría enunciarse la tesis general de que toda gran poesía es grande también en su forma métrica.

24 Véase Maria del Carmen Bobes Naves, La semiologia, Madrid, Síntesis, 1989, especialmente págs. 77-112. 
formas versificadas?; ¿cómo no utilizar los conceptos de la semántica semiótica para explicar, por ejemplo, la iconicidad o el valor simbólico de las formas métricas concretas, en general o en un poema determinado?; ¿cómo no entender en el marco de la pragmática las muchas implicaciones de tipo sociológico y cultural de la métrica a que me he referido antes?; ¿cómo no ver el esquema métrico como algo similar a un acto de lenguaje literario de la pragmática?

Por todas estas razones —que pueden resumirse en la conjunción del aspecto lingüístico y del histórico-convencional llevada a cabo por la semiótica-, pienso que ha llegado el momento en que los estudios métricos dejen de ser una parcela aislada, reservada a poquísimos especialistas, y empiecen a insertarse de forma natural en los proyectos de la moderna teoría literaria, de la semiótica actual ${ }^{25}$.

No quiero yo decir, ni mucho menos, que no se hayan dado pautas para explicar el valor semiótico de las formas métricas. La obra de Julia Kristeva demuestra, tanto en la teoría como en la referencia específica a la poesía moderna, que las estructuras métricas son factor importantísimo de la producción de sentido literario. En efecto, en su obra de teoría semiótica más conocida, ha explicado cómo la práctica semiótica del lenguaje poético ${ }^{26}$ como negatividad supone, aparte de un estatuto especial del significado poético (concreto no individual, referente no-referente, presencia del discurso extraño -intertextualidad, paragrammatismo-), unas propiedades lógicas de las articulaciones semánticas en el interior del texto poético; algunas de estas leyes particulares no

25 Véase J, Dominguez Caparrós, «Métrica y semiótica» en Da Semiótica (Actas do I Colóquio Luso-Espanhol, Porto, noviembre 1985), Lisboa, Vega, s.a. [1988], páginas 201 209.

${ }^{26}$ Aunque el lenguaje poético no es sinónimo de poesía, y engloba también a la "prosa», sin embargo, en palabras de la misma investigadora búlgara, es en la poesía donde se dan, de manera más llamativa y chocante, las particularidades de dicho lenguaje poético:

«Puisque ces particularités sont plus frappantes dans ce qu'on appelle la poésie, nous emprunterons nos exemples à cette dernière. Insistons pourtant sur le fait que le développement de la pratique littéraire depuis la fin du XIXe siècle, avant la science, efface désormais la distinction faite par la rhétorique traditionnelle entre 'prose' et 'poéssie'.» (Semeiotiké. Recherches pour une sémanalyse, París, Seuil, 1969, pág. 246, n. 1.)

Es lógico concluir que si las particularidades del lenguaje poético son más chocantes en to que no es "prosa», entonces las estructuras métricas tienen un papel importante en la «poeticidad», pues son estas estructuras las que señalan la diferencia entre prosa y poesía, según la terminología empleada por Julia KRISTEVA. 
son indiferentes, pienso yo, a las estructuras métricas. Según Julia Kristeva, estas leyes son:

1. La de idempotencia, que en la lengua corriente explica que la repetición de una unidad semántica no altera la significación del mensaje en todo caso, produce un efecto estilístico de fastidio o agramaticalidad-; en el lenguaje poético, sin embargo, toda repetición hace que la unidad repetida no sea la misma ${ }^{27}$.

2. La ley de commutabilidad: en la lengua corriente, el desplazamiento de unidades no cambia el significado; en la lengua poética, sin embargo, cualquier desplazamiento tiene como consecuencia un cambio mayor del sentido ${ }^{28}$.

No hay que insistir, pienso, en la importancia que la repetición y la disposición gráfica tienen en la métrica. Como muestra, léase la siguiente manifestación del poder significante de la disposición métrica:

«L'enoncé poétique n'est lisible dans sa totalité signifiante que comme une mise en espace des unités signifiantes. Chaque unité a sa place nettement définie et inaltérable dans le tout. Ce principe, latent et à l'oeuvre dans chaque texte poétique, est mis à jour lorsque la littérature prend conscience de son irreductibilité au langage parié, et Mallarmé en donne le premiuer exemple frappant ${ }^{29}$.»

La obra del poeta argentino Bernardo Schiavetta parece escrita para ilustrar precisamente las posibilidades de la métrica como práctica significante, como máquina productora de significado poético. La búsqueda de una motivación del signo poético está indicada en el mismo título, Fórmulas para Cratilo; que tal motivación se encuentra en la forma métrica, queda demostrado en todos los poemas que la componen. Como ejemplo, escogido al azar, léase el siguiente ${ }^{30}$.

27 Véase op. cit., págs. 258-259.

28 Véase op. cit., pág. 261.

29 Véase op. cit. pág. 262. En otro lugar me he referido al papel que J. LotMan asigna, en la artisticidad del texto, a los fenómenos métricos, desde el momento en que todo lo estructural tiene un significado artístico por ser ordenación y repetición. Véase mi trabajo «Métrica y semiótica», cit., págs. 206-207. De la obra de I. Lotman, La structure du texte artistique, París, Gallimard, 1973, son especialmente interesantes, para las cuestiones de métrica, los capítulos V, VI y VII.

30 Véase Bernardo Schiavetta, Fórmulas para Cratilo. Madrid, Visor, 1990, pág. 29. 


\author{
ESPEJO DEL EXORCISMO \\ eidolon \\ espejo del reflejo \\ endiablado y amado \\ espejismo y abismo \\ idolejo o diablejo \\ abismo y espejismo \\ amado y endiablado \\ reflejo del espejo
}

Aparte del quiasmo de la disposición, en espejo -el poema va reproduciendo, en orden inverso y a partir del quinto, los versos anteriores; la rima insiste en este orden-, pienso que hasta la igualdad precisa de la disposición gráfica de todos los versos es intencionada; $y$, por supuesto, la consonancia de las dos palabras llenas que componen cada uno de los versos. Estos son siete y cada uno tiene siete sílabas. No voy yo a poner en relación ahora estas cualidades formales con el semantismo del poema, porque no estoy preparado para hacer interpretaciones, más allá de lo que como lector pueda experimentar, sobre un posible psiquismo del juego o de la manía del orden; pero no niego, por supuesto, la evidente invitación que el poeta hace al lector a entregarse al endiablado y placentero juego con la apariencia del reflejo en el espejo.

Julia Kristeva ha señalado también la importancia que el aspecto fónico adquiere en la moderna poesía, después de la revolución que se da a finales del siglo XIX. La poesía moderna explota más las bases pulsionales de la fonación -constituidas por las regularidades sonoras subyacentes al sistema lingǘstico-, porque el sistema métrico ya no va al encuentro de una memoria nacional, sino que tiene que ver con la experiencia particular de cada sujeto. La crisis del verso hace que se exploten las bases pulsionales del ritmo, la aliteración, por ejemplo. Las reglas métricas, frente a las gramaticales -que son las que gobiernan al sujeto cartesiano-, estructuran la negativización de la posición tética (afirmativa) utilizando las articulaciones semióticas prelingüísticas; la métrica se relaciona con lo preconsciente ${ }^{31}$. El cambio político, por lo demás, afecta a la métrica, y si ésta, en su manifestación clásica, se asocia a la constitución de la identidad de una nación, en la moderna poesía, después que el capitalismo

31 Véase J. Kristeva, La révolution du langage poétique, París, Seuil, 1974 (Col. Points, n. 174,1985 ), pág. 217. Para las cuestiones que me interesan en este momento, véase el apartado titulado «Rythmes phoniques et sémantiques», págs. 209-263. 
ha consolidado la unidad nacional, sólo tiene que ver con la experiencia individual, como indica la búsqueda de una ritmicidad más profunda ${ }^{32}$. Como se ve, la organización formal del verso puede llegar a considerarse llena de sentido, poético e histórico.

No creo necesario seguir insistiendo en la poeticidad de las formas métricas, y en su pertenencia, por derecho propio, al grupo de objetos de estudio de la semiótica. Sólo quiero apuntar, muy brevemente, algunas indicaciones de cómo creo que puede orientarse actualmente el estudio concreto del verso español.

En primer lugar, hay que recordar que el análisis del verso, tarea de la métrica, suele ser enfocado de distintas maneras: centrándose en los principios que gobiernan el verso y los conceptos necesarios para su análisis (métrica teórica); es la especialidad fundamental, por ser la base de las otras. La métrica descriptiva se fija en las formas métricas empleadas por un autor, o en una época. La evolución de las formas métricas es el objeto de estudio de la métrica histórica, y la comparación de los sistemas de versificación de distintas literaturas es el fin de la métrica comparada.

La métrica teórica es, sin duda, esencial, porque sin ella difícilmente podrían realizarse una descripción, una historia o una comparación ${ }^{33}$. Pues bien, en la métrica teórica hay posibilidad de distinguir orientaciones bien caracterizadas. Hay una actitud apriorística, como la de la denominada métrica gráfico-lógica, que aplica los esquemas, definidos ya antes por la métrica clásica grecolatina, a la métrica moderna. La métrica musical, que concibe el verso como fenómeno semejante al de la música, con la que puede establecerse un paralelo, o la métrica acústica, interesada solamente en el aspecto fónico del verso, son maneras bien diferentes de analizar el fenómeno rítmico.

Aunque todas ellas resaltan algún aspecto objetivo del verso, tienen también carencias que las convierten en acercamientos parciales. Así, la métrica basada en la prosodia gráfico-lógica acierta en ver que detrás de un poema no hay únicamente sonido, sino esquemas generales; la métrica acústica acierta al analizar los elementos fónicos constitutivos del verso, aunque olvida que el verso no es sólo una cuestión de realización, de ejecución ${ }^{34}$.

El verso - - esta es la segunda observación general que quería hacer- es un hecho lingüístico; $y$, en el caso del verso español, las limitaciones le vienen impuestas por la lengua española. Si el español, por ejemplo, no utiliza

32 Véase op. cit., pág. 218.

33 Véase J. Dominguez Caparrós, Métrica y Poética, cit, pág. 33.

34 Véase J. Dominguez Caparrós, op. cit., págs. 38-40. 
fonológicamente las diferencias cuantitativas, el verso tampoco será cuantitativo.

En tercer lugar, el verso es un hecho del lenguaje, pero de lenguaje literario; lo que supone que es también un fenómeno convencional e histórico. Las implicaciones, para la explicación del verso español, son que no puede hablarse de un modelo de verso único, capaz de explicar la organización sistemática de todas las manifestaciones históricas. En este sentido, me parece que deben estudiarse, como sistemas distintos, el del verso anisosilábico medieval o popular; el del verso silábico culto medieval, o de origen italiano; el verso acentual de Juan de Mena; sin olvidar el verso acentual modemista, o el verso libre más reciente.

Hay, pues, un gran margen -entre las restricciones del sistema lingüístico y las convenciones de tipo histórico-_ en el que se manifiesta el verso con todas sus posibilidades de variación estilística; en este terreno es en el que la poética encuentra el campo propio de sus aportaciones al estudio métrico.

Por último, quiero decir que en la métrica hay mucho trabajo por realizar aún, en contra de una falsa impresión que parece dar por acabado y perfectamente aclarado el estudio del verso. Así, pienso que la métrica acústica tiene algo que decir todavía sobre las realizaciones - recepciones concretas del verso- y los modelos a que responden. Los viejos estudios de Eduardo Benot o de Felipe Robles Dégano, y los más recientes de A. Quilis sobre el encabalgamiento o de María Josefa Canellada y John Kuhlmann Madsen ${ }^{35}$ sobre pronunciación del español, tienen que ser continuados. De esta forma se comprenderá cómo pronunciamos hoy los versos, y se dejará, además, el testimonio para la historia de nuestra lengua.

Muchas son las parcelas que pueden acotarse, para su estudio, en métrica teórica. En primer lugar, queda por trazar el panorama con las grandes líneas de la historia de las teoría métricas en nuestro siglo. Y también hay suficiente producción teórica como para sistematizar el pensamiento sobre la versificación de épocas pasadas. Una investigación de conjunto sobre lo que se ha dicho acerca de la versificación medieval, no sería inútil. Tampoco falta materia para trabajar sobre importantes fenómenos concretos. En este sentido, está por hacer una monografía sobre la rima en la métrica española, por ejemplo, desde todos los puntos de vista.

Las investigaciones de Dorothy $\mathrm{C}$. Clarke sobre períodos concretos de nuestra versificación, o la gran síntesis histórica de Tomás Navarro Tomás, son modelos que deben tener continuación. Falta, por ejemplo, el panorama de las

35 Véase María Josefa Canellada y John Kulhmann Madsen, Pronunciación del español. Lengua hablada y literaria, Madrid, Castalia, 1987. 
tendencias rímicas de la versificación castellana de los últimos cincuenta años; y no me refiero a un estudio de sus valores estilísticos, sino a la más simple tarea de recuento de formas sobre el que posteriormente elaborar conclusiones de tipo estético. Muy escasos son igualmente los trabajos de métrica comparada que relacionen las modernas tendencias rítmicas de la poesía de distintas lenguas. Se impone, pues, la conclusión de que hay mucho por hacer aún en el estudio del verso español ${ }^{36}$.

36 Como punto de partida para la información bibliografica fundamental, puede verse: ALfredo Carballo Picazo, Métrica española, cit.; J. Domínguez Caparrós, Contribución a la bibliografía de los últimos treinta años sobre métrica española, cit. 